\title{
Intraoperative variations of the sphenopalatine artery between epistaxis and non-epistaxis cases: a comparative endoscopic analysis
}

\author{
Mostafa Ismail ${ }^{*}$, Abdelmoneim H. Hamad, Balegh Abdelhak and Khalaf Hamead
}

\begin{abstract}
Background: Severe epistaxis is one of the most common emergencies in rhinology practices. The commonly used endoscopic cauterization of the sphenopalatine artery (SPA), alone or with the anterior ethmoidal artery (AEA), has a high success rate for controlling severe epistaxis. The current study was conducted to evaluate the endoscopic intra-operative variations of SPA between epistaxis and non-epistaxis cases. Forty consecutive patients who underwent exploration of SPA were included in the study. They were distributed into two groups depending upon the indication of SPA exploration; the epistaxis group (group A, $n=25$ patients, $n=26$ sides) and the non-epistaxis group (group $B, n=15$ patients, $n=25$ sides). Criteria of the main SPA in the two groups were compared regarding four parameters; arterial diameter, arterial adherence to the mucosa of the lower part of the basal lamella, sphenopalatine nerve bundle, and crista ethmoidalis erosion.

Results: A significant difference was found regarding the diameter of SPA between the two groups; a mean diameter of $4.2 \pm 0.64 \mathrm{~mm}$ was compared to $3.2 \pm 0.35 \mathrm{~mm}$ for group $A$ and $B$, respectively $(p=0.043)$. Moreover, a highly significant tendency was observed regarding the arterial adherence to the mucosa of the lower part of the basal lamella and sphenopalatine nerve bundle in the epistaxis group; $(p \leq 0.01)$.

Conclusion: These data clearly signify the importance of intraoperative identification of SPA criteria during surgical management of severe epistaxis. These criteria may help in altering the surgical decision between solely SPA and concomitant SPA/AEA cauterization.
\end{abstract}

Keywords: Severe epistaxis, Sphenopalatine artery, Endoscopic cauterization, Anterior ethmoidal artery

\section{Background}

The existence of a consensus protocol in the staggered application of surgical treatments of severe epistaxis, aiming at the correct intraoperative identification of the bleeding point, is of vital importance. The lack of a universal management protocol and the difficulty to identify the bleeding source, in most cases of severe epistaxis [1, 2], have given rise to many surgical paradigms targeting the empirical ligation and/or cauterization of main feeding

\footnotetext{
* Correspondence: mostafaismail3730@yahoo.com

Department of Otorhinolaryngology, Minia University Hospital, Minia University, Kornish El Nile St. El Minia, Minya, Egypt
}

blood vessels of the nasal mucosa. The selected surgical paradigm depends mainly upon the surgeon's own experience and his/her expectation for the source of bleeding.

Like any surgical procedure, there is a learning curve in order to consistently perform safe and efficient surgery. The management paradigms of severe epistaxis have evolved from enormous measures to more concise and less invasive procedures [3]. Recently, the endoscopic ligation and/or cauterization of SPA and its terminal branches has been the commonly used surgical procedure for controlling severe epistaxis. A concomitant endoscopic SPA/AEA ligation and/or cauterization

\section{Springer Open}

(0) The Author(s). 2021 Open Access This article is licensed under a Creative Commons Attribution 4.0 International License, which permits use, sharing, adaptation, distribution and reproduction in any medium or format, as long as you give appropriate credit to the original author(s) and the source, provide a link to the Creative Commons licence, and indicate if changes were made. The images or other third party material in this article are included in the article's Creative Commons licence, unless indicated otherwise in a credit line to the material. If material is not included in the article's Creative Commons licence and your intended use is not permitted by statutory regulation or exceeds the permitted use, you will need to obtain permission directly from the copyright holder. To view a copy of this licence, visit http://creativecommons.org/licenses/by/4.0/. 
may be considered if the source of bleeding could not be identified pre-operatively [4-6].

With anatomical variations of the arteries supplying the nasal cavity, particularly the main SPA and its terminal branches $[7,8]$, the likelihood of recurrent epistaxis is ever so often present $[5,9,10]$. The risk of recurrent epistaxis has been always associated with the preoperative localization of bleeding source, surgeon's experience, intraoperative visualization, and presence of anatomical variations [11]. In surgery, the key for the efficient control of severe epistaxis is the accurate identification of bleeding source that is similarly necessary for selecting the appropriate management procedure $[5,6,12-14]$.

No previous studies had focused on a thorough analysis of SPA variations in the surgical trajectory between epistaxis and non-epistaxis cases. Therefore, we have conducted this work to evaluate the intraoperative variations of SPA between epistaxis and nonepistaxis cases while taking into account the endoscopic perspective. This information can be of great help in the operative training and can also provide a base for future studies to help the intraoperative confirmation of bleeding source in an attempt to refine the paradigm of surgical management of severe epistaxis.

\section{Methods}

\section{Study design}

We have conducted a comparative evaluation of SPA variations during surgical exploration of the artery in the operative theater at our institution. The study included 40 consecutive patients who underwent exploration with or without cauterization of SPA between January 2018 and November 2019. They were distributed into two groups depending upon the indication of SPA exploration. The first group (group A); epistaxis group $(n=25)$, in which all patients underwent endoscopic exploration and cauterization of SPA for controlling severe refractory epistaxis (unilateral; $n=24$ and bilateral; $n=1$; total nasal sides; $n=26$ ). The second group (group B); nonepistaxis group $(n=15)$, in which all patients underwent exploration of SPA as a part of another surgical procedure; bilateral posterior nasal neurectomy for refractory nasal allergy $(n=10)$, unilateral medial maxillectomy for inverted papilloma (the tumor was arising from the lateral nasal wall away from the region of SPA in all cases, $n=4$ ), and unilateral trans-pterygoidal approach for repair of spontaneous CSF leak from lateral recess sphenoid sinus $(n=1)$; (total nasal sides; $n=25$ ). The study was approved by the Committee for Medical Research Ethics. All patients signed a written consent prior to being included in the study.
Exclusion criteria were the patients aged $<18$ years, patients on blood pressure medications, history of previous sinonasal surgery, and patients with coagulopathy.

\section{Surgical procedure}

All cases from both groups underwent surgical exploration with or without cauterization of the SPA under general anesthesia. We proposed the delineation of a target area on the lateral nasal wall for identification of the SPA instead of depending upon fixed landmarks that may be variable or even absent. The proposed area is located between the posterior medial maxillary wall; superiorly, the posterior end of the middle turbinate; inferiorly, the junction between the lower part of the basal lamella and perpendicular plate of palatine bone; posteriorly and the superior border of the inferior turbinate; anteriorly (Fig. 1).

A vertical incision was made on the mucosa of the perpendicular plate of the palatine bone; $8-10 \mathrm{~mm}$ from the posterior end of the middle turbinate, starting from under the basal lamella of the middle turbinate and continued along, not beyond, the superior border of the inferior turbinate. A freer elevator was used to dissect the mucoperiosteum from the perpendicular plate of palatine bone starting anteriorly just above the inferior turbinate and continued posteriorly till the exposure of the sphenopalatine foramen with the sphenopalatine neurovascular pedicle exiting the foramen. The crista ethmoidalis of the palatine bone can be seen directly anterior to the sphenopalatine foramen, and it was completely removed using a 2-mm Kerrison rongeur for greater exposure of the main arterial trunk. The dissection was continued far posteriorly till the anterior wall of the sphenoid sinus to be sure of not missing any other accessory arterial branches; particularly in the epistaxis group.

In the epistaxis group, once it was clearly exposed, a bipolar electrocautery was placed on the main artery for its cauterization with subsequent cauterization of its two major branches; the posterior lateral and posterior septal arteries plus the accessory arterial branches, if present. In the non-epistaxis group, the main SPA was explored, then the sphenopalatine nerve bundle was separated and cut from the vascular pedicle, bilaterally, without cauterization of SPA, in all cases of posterior nasal neurectomy. The main SPA was explored and cauterized in the other cases of medial maxillectomy and transpterygoidal approach to the lateral recess of sphenoid sinus.

\section{Analysis of SPA criteria}

Data collected from both groups was analyzed regarding 4 criteria of the main SPA that were defined in a preoperative survey. The diameter of the main arterial trunk 


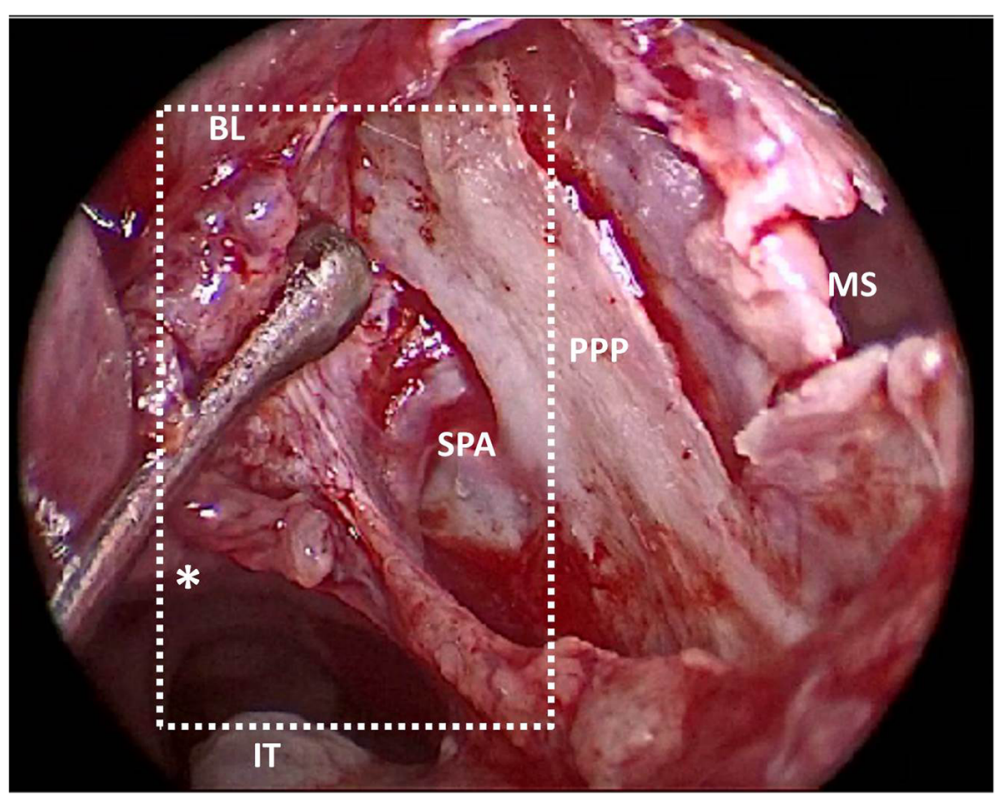

Fig. 1 Picture of a left nasal cavity showing details of the target area on the lateral nasal wall for identification of SPA. In the superior border, the posterior medial maxillary wall. The posterior end of the middle turbinate $\left.{ }^{*}\right)$ is the inferior border. The junction between the basal lamella and perpendicular plate of palatine bone is the posterior border. In the anterior border, the superior edge of the inferior turbinate. BL basal lamella, SPA sphenopalatine artery, PPP perpendicular plate of the palatine bone, IT inferior turbinate, MS maxillary sinus

was measured at a midpoint between the foramen and mucosal arterial ends and was taken on a millimetric scale prior to arterial cauterization. The adherence of the main artery to the mucosa of the lower part of the basal lamella of the middle turbinate and the sphenopalatine nerve bundle was tested using a small blunt dissector. Erosion of Crista ethmoidalis of the palatine bone was evaluated in all cases. All measurements were carried out intraoperatively.

\section{Statistical analysis}

Statistical analyses were performed using IBM SPSS 22.0. A comparative statistical analysis of all variables was carried out using Student's $t$ test and Fisher's exact test. The level of significance was set at $p<0.05$ for both tests.

Table 1 Group details

\begin{tabular}{lll}
\hline & Groups \\
\cline { 2 - 3 } & A & B \\
\hline Gender (male to female) & $(13: 12)$ & $(11: 9)$ \\
Age (years), mean \pm SD & $34.4 \pm 1.1$ & $33.7 \pm 1.03$ \\
Laterality (right to left), $n$ & $(14: 9)$ & $(1: 4)$ \\
Bilateral, $n$ & 2 & 10 \\
Total of nasal sides, $n$ (\%) & $27(51.9 \%)$ & $25(48.1 \%)$ \\
Single SPA (nasal sides), $n$ & 22 & 23 \\
Accessory SPA (nasal sides), $n$ & 5 & 2 \\
\hline
\end{tabular}

SD standard deviation, SPA sphenopalatine artery

\section{Results}

The results obtained from both groups are summarized in (Table 1). A total of $47 \%$ of patients were females and $53 \%$ males, aged between 19 and 58 years (a mean of 34.1 years). In group A, SPA was explored and cauterized unilaterally in 24 cases and bilaterally in 1 case; (total $n=26$ sides). In group B, SPA was explored bilaterally in the 10 cases of posterior nasal neurectomy, while it was explored and cauterized on one side in the remaining 5 cases (total $n=25$ sides).

All the intraoperative assessed parameters of all SPAs are shown in (Table 2). In group A (epistaxis group), the average diameter of the intermediate portion of the main arterial trunk was $4.2 \pm 0.64 \mathrm{~mm}$, ranging between 3 and $6 \mathrm{~mm}$ (Fig. 2a, b). In group B (non-epistaxis group), the average diameter of the intermediate portion of the main arterial trunk was $3.2 \pm 0.35 \mathrm{~mm}$, ranging between 2.5

Table 2 Intraoperative differences between groups

\begin{tabular}{|c|c|c|c|}
\hline \multirow[t]{2}{*}{ Variable } & \multicolumn{2}{|l|}{ Groups } & \multirow{2}{*}{$\begin{array}{l}P \\
\text { value }\end{array}$} \\
\hline & A & B & \\
\hline Mean arterial diameter \pm SD (mm) & $4.24 \pm 0.64$ & $3.18 \pm 0.35$ & 0.043 \\
\hline Adherence to mucosa of basal lamella & $24(88.9 \%)$ & $1(4 \%)$ & $<0.01$ \\
\hline Adherence to SP nerve bundle & $21(77.8 \%)$ & $5(20 \%)$ & $<0.01$ \\
\hline Crista ethmoidalis erosion & $14(51.9 \%)$ & $7(28 \%)$ & 0.097 \\
\hline Total of nasal sides & $27(51.9 \%)$ & $25(48.1 \%)$ & \\
\hline
\end{tabular}

*Bold values are significant

$S P$ sphenopalatine 

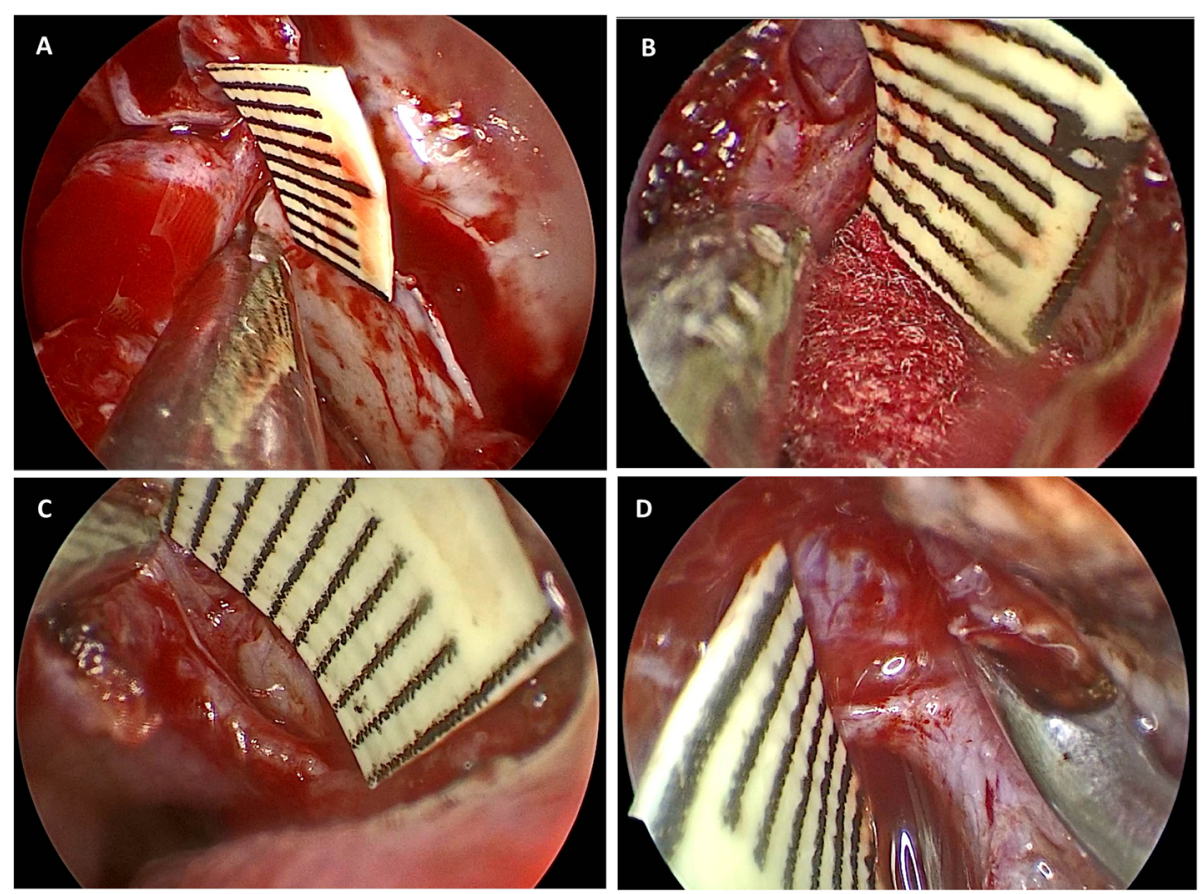

Fig. 2 a-d Intraoperative measurement variations of SPA diameter between 2 groups. a, b 2 cases from group A; 4.5-mm and 5-mm diameter, respectively. $\mathbf{c}, \mathbf{d} 2$ cases from group B; 3-mm diameter for both

and $3.5 \mathrm{~mm}$ (Fig. 2c, d). By comparing arterial diameter between both groups, in the epistaxis group (A), the mean SPA diameter was found to be statistically significantly larger than in the non-epistaxis group (B) $(4.2$ $\mathrm{mm}$ vs $3.2 \mathrm{~mm} ; p=0.043)$.

A tendency was observed regarding the arterial adherence to the mucosa of the lower part of the basal lamella and the sphenopalatine nerve bundle in the epistaxis group with a high significant difference for both variables ( $p \leq 0.01$ for both). The main SPA was found inseparable from the mucosa of the lower part of the basal lamella and amalgamated with the sphenopalatine nerve bundle, in $89 \%$ and $78 \%$, respectively, of all explored nasal sides, in group A, while it was clearly separable from both, in $96 \%$ and $80 \%$, respectively, in group B (Fig. 3a-f). The incidence of crista ethmoidalis erosion was also higher in the epistaxis group (Fig. 4a-d), but without statistical significance $(52 \%$ vs $28 \% ; p=0.097)$.

In the epistaxis group, a mean of 6 months follow-up showed a successful control of severe epistaxis except in 3 cases. A retrospective review of medical records has identified 3 nasal sides with a main arterial trunk diameter less than the measured mean diameter of this group. In correlation with operative data, these were as follows: 2 sides with $3.5 \mathrm{~mm}$ diameter and $3 \mathrm{~mm}$ for the one side. Moreover, the adherence of the main SPA with the mucosa of the lower part of the basal lamella and sphenopalatine nerve bundle was missed in the 3 nasal sides.
The 3 patients of recurrent epistaxis were readmitted for endoscopic exploration of the sphenopalatine region. No missed arterial trunks were recorded in any case. This was followed by an endoscopic exploration of the region of AEA, and a bipolar diathermy was used to cauterize the vessel with subsequent control of epistaxis.

\section{Discussion}

Despite progress in the endoscopic techniques and training for surgical management of severe epistaxis, both failure to control epistaxis and recurrences continue to occur. A retrospective audit was performed in 2002 over a 2-year period to examine the efficacy of endoscopic SPA ligation and/or cauterization, and the failure rate was 33\% [15]. In 2014, a systematic review has shown a failure rate ranging between $3 \%$ and $8 \%$. In the latter review, failure rates were inferred due to that it was part of a learning curve, the often-indeterminate site of epistaxis despite endoscopic examination and the variable branching pattern of the SPA [4].

In the same systematic review, the endoscopic ligation and/or cauterization of AEA was described as a common cause of controlling recurrent epistaxis when it was performed either concomitantly with or after SPA cauterization [4]. This observation was again highlighted in similar studies over the past years $[1,12,16]$. These data clearly signify that the efficient identification of bleeding source during surgical management of severe epistaxis remains challenging in certain cases and 

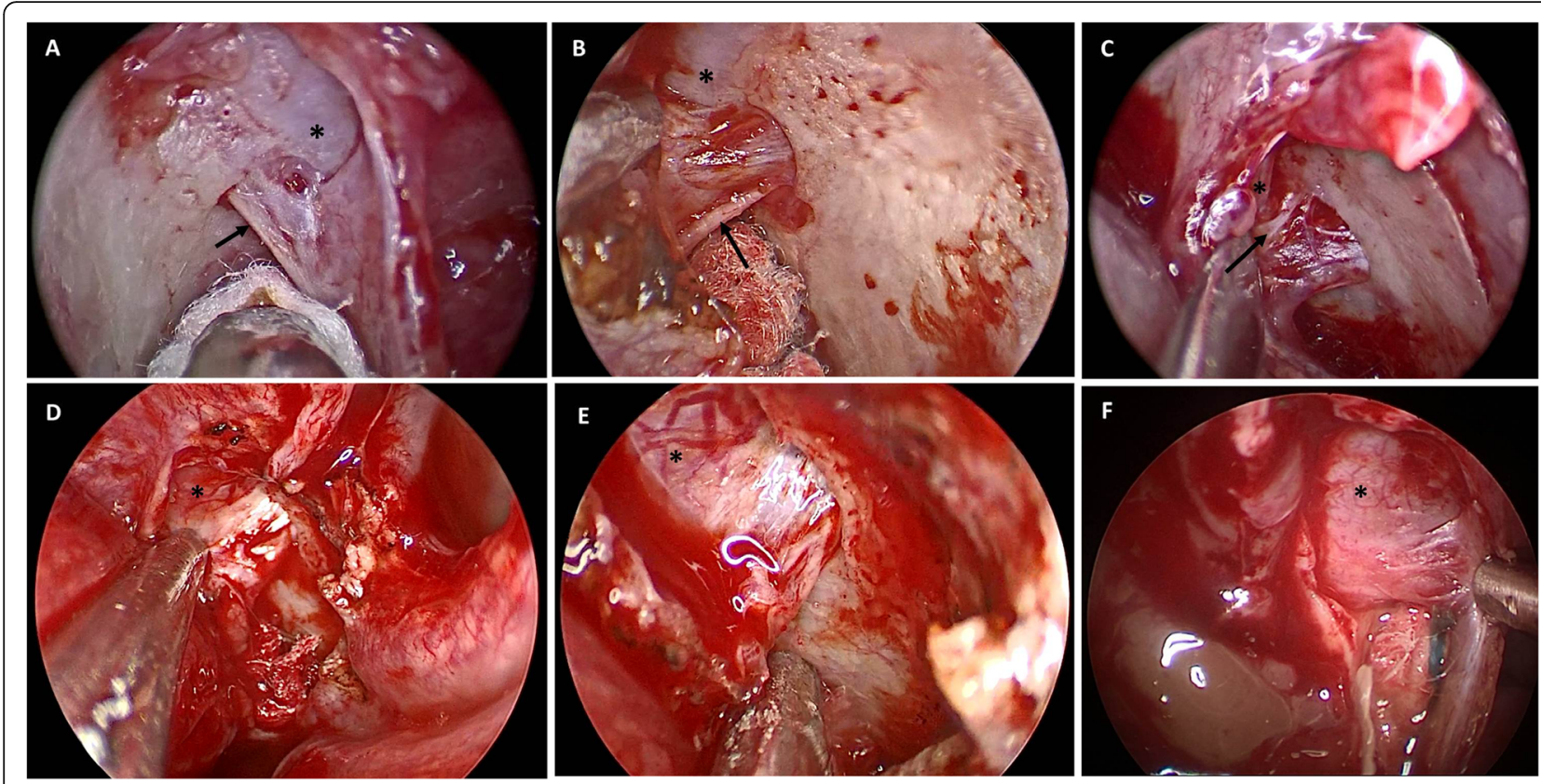

Fig. 3 a-f Intraoperative endoscopic pictures from both groups showing the variable relationship of SPA with the mucosa of the lower part of basal lamella (black star) and sphenopalatine nerve bundle (black arrow); it was separable from the main arterial trunk in the non-epistaxis group (a-c) and amalgamated, inseparable in epistaxis group (d-f)
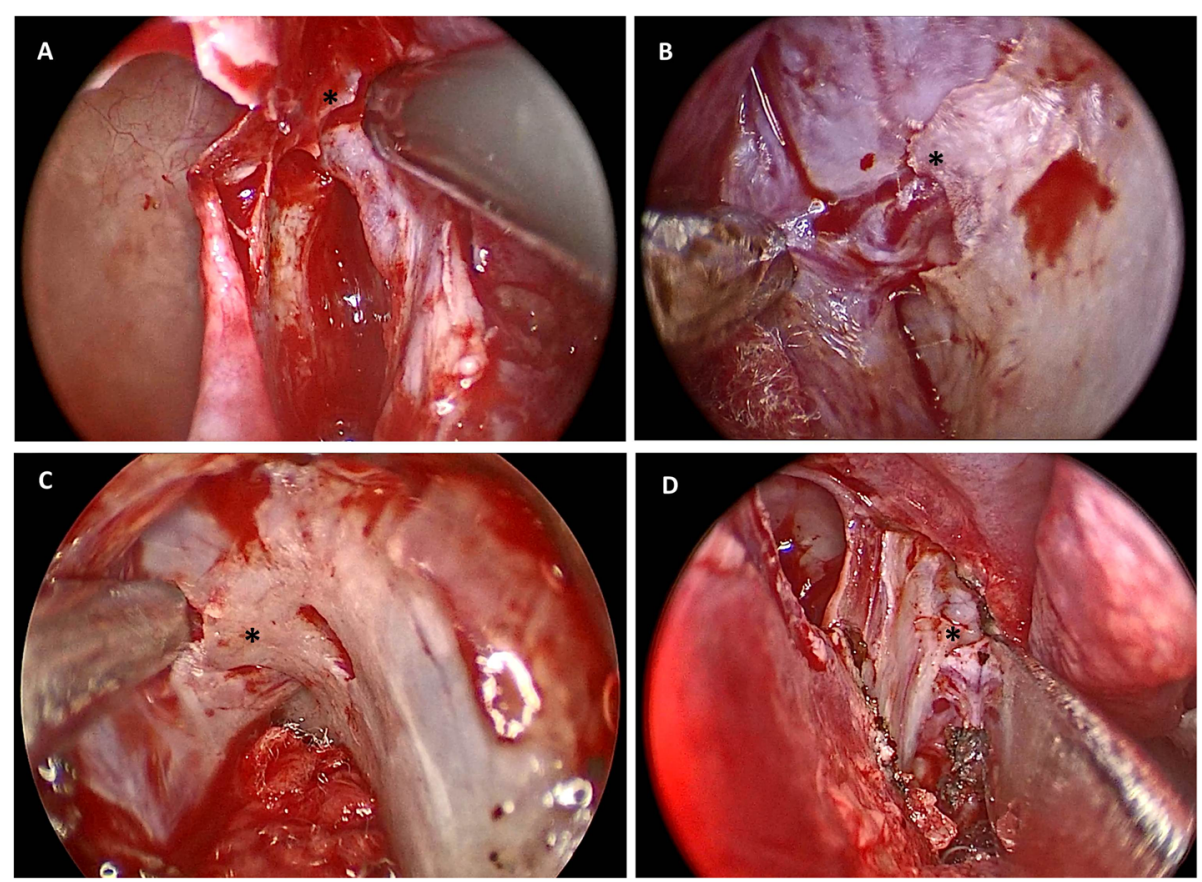

Fig. 4 a-d Endoscopic view of Crista ethmoidalis (black star); it was partially eroded in 2 cases from epistaxis group (a, b) and intact in 2 cases from the non-epistaxis group (c, d) 
probably for some surgeons. However, it has been still a subject of great controversy, whether to control AEA concomitantly with SPA cauterization $[4,16]$ or to keep it for recurrent cases [15-19] and which of these procedures will be responsible for the successful control of epistaxis [12].

In our study, when comparing the intraoperative characters of SPA in the current 2 study groups, some points should be highlighted. In the epistaxis group, the mean SPA diameter was found to be statistically significantly larger than in the non-epistaxis group (B) $(4.2 \mathrm{~mm}$ vs $3.2 \mathrm{~mm} ; p=0.043$ ). It should be also noted that many previous studies reported a smaller arterial diameter range of $1.5-2.4 \mathrm{~mm}[8,20-23]$. However, the thorough analysis of SPA variations in such studies was performed postmortem in cadavers.

In this comparative work, the incidence of arterial adherence with the mucosa of the lower part of the basal lamella and the sphenopalatine nerve bundle was higher in the epistaxis group $(89 \%$ and $78 \%$, respectively) when compared with the non-epistaxis group ( $4 \%$ and $20 \%$, respectively). Our explanation for this finding that recurrent attacks of bleeding may lead to minor arterial surface inflammations causing arterial adherence to the surrounding mucosal and nerve structures. Since the preoperative duration of epistaxis may be potentially influenced the erosion rate of crista ethmoidalis and such erosion could be just an anatomical variant due to the vessel location, we had to acknowledge the limitation of using the incidence of crista ethmoidalis erosion as a definite sign for the source of epistaxis.
It is worth mentioning that, in the current study, the failure rate of the endoscopic cauterization of SPA was $(11.1 \%, n=3)$. Interestingly, all failures showed a smaller diameter of the main arterial trunk less than the mean diameter of the epistaxis group $(4.2 \pm 0.64 \mathrm{~mm})$ and also lacked adherence with the mucosa of the lower part of the basal lamella and sphenopalatine nerve bundle. All three failures required AEA exploration and cauterization with subsequent control of epistaxis, and this means that in those 3 cases, the cause of failure was that the AEA was the source of bleeding in these cases. It was noted in several previous studies that improved control of severe epistaxis occurred when combining SPA/AEA cauterization, and it would reduce the number of theater returns $[1,4,5,16,24]$. The authors suggest that it may be prudent to control the AEA with the SPA in cases lacking two or more of the following arterial criteria (arterial diameter $\leq 4$, adherence to the mucosa of the lower part of the basal lamella, adherence to the mucosa of sphenopalatine nerve bundle).

The SPA variations presented in the current study are not meant to ask the surgeon to take measurements intraoperatively, but instead to improve surgeons' awareness of the intraoperative identification of the SPA criteria and to give him or her an estimate about when to perform a sole cauterization of SPA and when it should be combined with AEA cauterization for surgical management of severe epistaxis. This is clearly highlighted in our flow diagram for surgical management of severe epistaxis (Fig. 5).

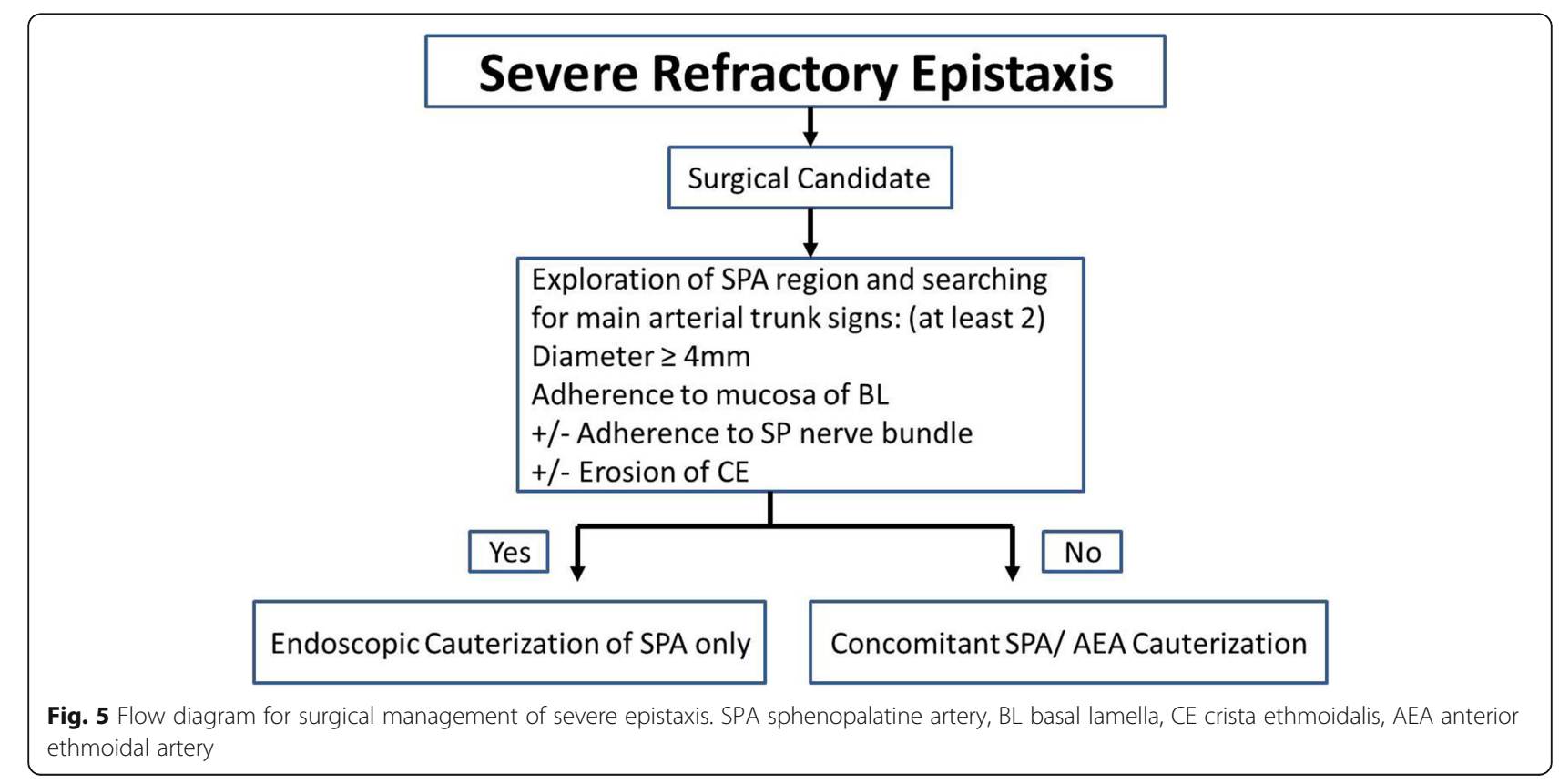




\section{Conclusion}

It might be helpful to recall the intraoperative active search for SPA criteria during surgical management of severe epistaxis. Attention to these criteria may similarly help surgeons to get a step forward in performing closely efficient endoscopic control of severe epistaxis. This information can help in surgical training and may also assist in defining surgical management scenarios of severe epistaxis.

\section{Abbreviations \\ SPA: Sphenopalatine artery; AEA: Anterior ethmoidal artery; CSF: Cerebrospinal fluid}

\section{Acknowledgements}

Not applicable.

\section{Authors' contributions}

M.l: Design of the work, analysis of data, interpretation of data, and revising the manuscript. A.H: Acquisition and analysis of data. B.A: Designing of study and data analysis. K.H: Designing of study and interpretation of data. The authors have read and approved the manuscript

\section{Funding}

The authors declare that they have no funding resources.

\section{Availability of data and materials}

Not applicable.

\section{Declarations}

\section{Ethics approval and consent to participate}

The study was approved by the Committee for Medical Research Ethics in Minia University, Faculty of Medicine, Egypt. The reference number is not available as at the time this research was performed, the committee was not fully activated. All patients signed a written consent prior being included in the study.

\section{Consent for publication}

A consent for publication was obtained from patients prior to being included in the study. All patients realized that the material will be published without their name attached and the article may be published in a journal which is distributed worldwide and also the article, including the material, may be the subject of a press release and may be linked to from social media and/or used in other promotional activities.

\section{Competing interests}

The authors declare that they have no competing interests.

Received: 15 December 2020 Accepted: 18 March 2021

\section{Published online: 06 April 2021}

\section{References}

1. Saraceni Neto P, Nunes LMA, Gregório LC, Santos RD, Kosugi EM (2013) Surgical treatment of severe epistaxis: an eleven-year experience. Brazilian J Otorhinolaryngol 79(1):59-64. https://doi.org/10.5935/1808-8694.20130011

2. Almeida GS, Diógenes CA, Pinheiro SD (2005) Nasal endoscopy and localization of the bleeding source in epistaxis: last decade's revolution. Rev Bras Otorrinolaringol 71(2):146-148. https://doi.org/10.1016/s1808-8694 (15)31302-1

3. Kosugi EM, Balsalobre L, Mangussi-Gomes J, Tepedino MS, San-da-Silva DM, Cabernite EM, Hermann D, Stamm AC (2018) Breaking paradigms in severe epistaxis: the importance of looking for the S-point. Brazilian Journal of otorhinolaryngology 84(3):290-297. https://doi.org/10.1016/j. bjorl.2017.12.007

4. McClurg S, Carrau R (2014) Endoscopic management of posterior epistaxis: a review. Acta Otorhinolaryngol Ital 34(1):1-8

5. Snyderman CH, Goldman SA, Carrau RL, Ferguson BJ, Grandis JR (1999) Endoscopic sphenopalatine artery ligation is an effective method of treatment for posterior epistaxis. Am J Rhinol 13(2):137-140. https://doi. org/10.2500/105065899782106805

6. Gurney TA, Dowd CF, Murr AH (2004) Embolization for the treatment of idiopathic posterior epistaxis. Am J Rhinol 18(5):335-339. https://doi.org/1 $0.1177 / 194589240401800513$

7. Prades J, Asanau A, Timoshenko A, Faye M, Martin C (2008) Surgical anatomy of the sphenopalatine foramen and its arterial content. Surg Radiol Anat 30(7):583-587. https://doi.org/10.1007/s00276-008-0390-x

8. Lee HY, Kim HU, Kim SS, Son EJ, Kim JW, Cho NH, Kim KS, Lee JG, Chung $\mathbb{H}_{\text {, }}$ Yoon JH (2002) Surgical anatomy of the sphenopalatine artery in lateral nasal wall. Laryngoscope 112(10):1813-1818. https://doi.org/10.1097/ 00005537-200210000-00020

9. O'flynn P, Shadaba A (2000) Management of posterior epistaxis by endoscopic clipping of the sphenopalatine artery. Clin Otolaryngol Allied Sci 25(5):374-377. https://doi.org/10.1046/j.1365-2273.2000.00372.x

10. Ram B, White PS, Saleh HA, Odutoye T, Cain A (2000) Endoscopic endonasal ligation of the sphenopalatine artery. Rhinology. 38(3):147-149

11. Rezende GL, Soares VYR, Moraes WC, de Oliveira CACP, Nakanishi M (2012) The sphenopalatine artery: a surgical challenge in epistaxis. $\mathrm{Br}$ Otorhinolaryngol 78(4):42-47. https://doi.org/10.1590/\$1808-869420120004 00009

12. Pletcher SD, Metson R (2007) Endoscopic ligation of the anterior ethmoid artery. Laryngoscope 117(2):378-381. https://doi.org/10.1097/01.mlg.00002 50778.29957.a1

13. Douglas S, Gupta D (2003) Endoscopic assisted external approach anterior ethmoidal artery ligation for the management of epistaxis. J Laryngol Otol 117(2):132-133. https://doi.org/10.1258/002221503762624594

14. Chiu TW, McGarry GW (2007) Prospective clinical study of bleeding sites in idiopathic adult posterior epistaxis. Otolaryngol Head Neck Surg 137(3):390393. https://doi.org/10.1016/j.otohns.2006.10.035

15. Rockey J, Anand R (2002) A critical audit of the surgical management of intractable epistaxis using sphenopalatine artery ligation/diathermy. Rhinology. 40(3):147-149

16. Kumar S, Shetty A, Rockey J, Nilssen E (2003) Contemporary surgical treatment of epistaxis. What is the evidence for sphenopalatine artery ligation? Clin Otolaryngol Allied Sci 28(4):360-363. https://doi.org/10.1046/ j.1365-2273.2003.00724.x

17. Holzmann D, Kaufmann T, Pedrini P, Valavanis A (2003) Posterior epistaxis: endonasal exposure and occlusion of the branches of the sphenopalatine artery. Eur Arch Otorhinolaryngol 260(8):425-428. https://doi.org/10.1007/ s00405-003-0618-7

18. Thornton MA, Mahesh BN, Lang J (2005) Posterior epistaxis: identification of common bleeding sites. Laryngoscope 115(4):588-590. https://doi.org/10.1 097/01.mlg.0000161365.96685.6c

19. Saraceni Neto P, Nunes LM, Caparroz FD, Gregorio LL, de Souza RD, Simões JC, Kosugi EM et al (2017) Resection of the ethmoidal crest in sphenopalatine artery surgery. Int Forum Allergy Rhinol 2017:87-90

20. Stamm AC, Ferreira GP, Navarro JAC, Freire LAS (2000) Severe epistaxis: micro-endoscopic surgical techniques. In: Micro-endoscopic surgery of the paranasal sinuses and the skull base. Springer, Berlin, pp 393-403. https:// doi.org/10.1007/978-3-642-57153-4_32

21. Floreani SR, Nair SB, Switajewski MC, Wormald PJ (2006) Endoscopic anterior ethmoidal artery ligation: a cadaver study. Laryngoscope. 116(7):1263-1267. https://doi.org/10.1097/01.mlg.0000221967.67003.1d

22. Nalavenkata S, Meller C, Novakovic D, Forer M, Patel N (2015) Sphenopalatine foramen: endoscopic approach with bony landmarks. J Laryngol Otol 129(S3):S47-S52. https://doi.org/10.1017/S0022215115000766

23. Wang S, Zhang J, Xue L, Wei L, Xi Z, Wang R (2015) Anatomy and CT reconstruction of the anterior area of sphenoid sinus. Int J Clin Exp Med 8(4):5217 Published 2015 Apr 15

24. Singh B, Med M (1992) Combined internal maxillary and anterior ethmoidal arterial occlusion: the treatment of choice in intractable epistaxis. J Laryngol Otol 106(6):507-510. https://doi.org/10.1017/S0022215100120006

\section{Publisher's Note}

Springer Nature remains neutral with regard to jurisdictional claims in published maps and institutional affiliations. 